\title{
Widespread Occurrence and Diversity of Cassava brown streak virus (Potyviridae: Ipomovirus) in Tanzania
}

\author{
G. M. Rwegasira, G. Momanyi, M. E. C. Rey, G. Kahwa, and J. P. Legg
}

First author: Department of Crop Science and Production, Sokoine University of Agriculture, P.O. Box 3005 Chuo Kikuu, Morogoro, Tanzania; School of Molecular and Cell Biology, University of the Witwatersrand, Johannesburg, Private Bag 3, Wits 2050, South Africa; and International Institute of Tropical Agriculture, P.O. Box 34441, Dar-es-Salaam, Tanzania; second, fourth, and fifth authors: International Institute of Tropical Agriculture, P.O. Box 34441, Dar-es-Salaam, Tanzania; and third author: School of Molecular and Cell Biology, University of the Witwatersrand.

Accepted for publication 18 April 2011.

\section{ABSTRACT}

Rwegasira, G. M., Momanyi, G., Rey, M. E. C., Kahwa, G., and Legg, J. P. 2011. Widespread occurrence and diversity of Cassava brown streak virus (Potyviridae: Ipomovirus) in Tanzania. Phytopathology 101:11591167.

Cassava brown streak disease (CBSD) has been a problem in Tanzania since 1936. Existing literature indicated limited distribution of the disease to low altitudes, usually $<100 \mathrm{~m}$ above sea level, but the current geographical distribution of the disease was not known. Whether a single or many strains for the virus exist in Tanzania had not been reported to date. In this study, CBSD was recorded from sea level to $\approx 1,800 \mathrm{~m}$ above sea level. In total, 2,730 cassava plants were assessed for CBSD leaf symptoms in 91 fields and root symptoms were assessed at 81 sites. A sample was taken from each site for laboratory screening for Cassava brown streak virus (CBSV). CBSD mean foliar and root incidences were 38 and $36 \%$, respectively. Reverse-transcription polymerase chain reac- tion of a partial $3^{\prime}$-terminal coat protein $(\mathrm{CP})$ region of CBSV indicated the presence of CBSV in 67 of the 91 (73\%) samples. Forty-three amplicons were sequenced, and phylogenetic comparisons with nucleotide sequences from GenBank (National Center for Biotechnology Information database) suggested that one major clade of CBSV primarily exists in Tanzania. However, there was nucleotide sequence divergence of up to $19 \%$ among the 42 isolates. In all, 42 of the 43 sequences had 80 to $100 \%$ nucleotide identity with 6 previously reported CP-CBSV sequences (from Mozambique and Tanzania). In total, 13 of 42 isolates had $<80 \%$ nucleotide identities with three previously reported Ugandan CBSV sequences. One isolate, FJ687177, shared $<78 \%$ sequence identity with the other Tanzanian sequences but was closely related (93\%) to Ugandan isolates. It is likely that isolate FJ687177 may belong to a less widely distributed recently described species (clade 2) of CBSV, named Ugandan cassava brown streak virus (UCBSV).
Cassava brown streak disease (CBSD) is caused by cassava brown streak viruses (CBSVs) (family Potyviridae; genus Ipomovirus) $(1,17,32)$. Two species of CBSVs are currently recognized: Cassava brown streak virus (CBSV) and Ugandan cassava brown streak virus (UCBSV) $(26,27,43)$. This newly described species, UCBSV, was named at the ICTV in June 2010, and has been associated with higher altitudes $>1,000 \mathrm{~m}$ above sea level (masl) in Uganda (25). It has now also been shown that CBSV and UCBSV occur commonly in mixed infections (27). CBSD was first reported in coastal Tanzania $>70$ years ago (38). The disease was present at altitudes of 500 to 1,000 masl but damage was most severe at elevations below 500 masl $(16,34,39)$. The geographical distribution of CBSD included all East African coastal areas extending from the northeast border of Kenya to Mozambique, and included the low-altitude areas in Malawi, particularly along the shores of Lake Malawi $(12,19,34)$.

Early studies on the possible causal agent, mechanism of spread, and management of the disease through resistant cultivars were conducted at Amani Research Station in northeastern colonial Tanganyika $(18,32,38)$, and the first detailed description of the disease was given in the 1950s (34). The brown mass of necrotic inclusions in the root cortex of affected plants was established as the most damaging symptom associated with the disease $(18,38)$.

Corresponding author: M. E. C. Rey; E-mail address: chrissie.Rey@wits.ac.za

doi:10.1094/PHYTO-11-10-0297

(C) 2011 The American Phytopathological Society
The highest yield loss, in terms of fresh roots was estimated at $70 \%$ from Tanzania $(14,33)$.

In 1950, CBSD was widely distributed (34) in the eastern coastal areas of Tanzania. The disease was reported to spread through infected cuttings $(15,19,34,41)$. More recently, the whitefly Bemisia tabaci (Gennadius) (Hemiptera: Aleyrodidae), was shown to transmit CBSVs, albeit with low transmission efficiency (23). Reports of an outbreak of CBSD in Uganda from $2004(2,3)$ confirmed that the disease had spread to areas above 1,000 masl and was particularly apparent in resistant cultivars that were specifically bred to counteract the cassava mosaic disease (CMD) pandemic. CMD is caused by a group of cassava mosaic geminiviruses (CMGs) (family Geminiviridae; genus Begomovirus) and is endemic to sub-Saharan Africa $(5,24)$. In the field, CBSD has been reported to occur together with CMD due to dual infection by the causal viruses (15). The study reported here was conducted to determine the status of CBSD and CBSVs in Tanzania. This represents the most extensive and comprehensive CBSD survey undertaken to date in the country, and considered farmers' cassava fields in 19 regions.

\section{MATERIALS AND METHODS}

Field survey. In total, 91 farmers' cassava fields in 19 regions were assessed for incidence and severity of CBSD in all the major cassava-growing areas of Tanzania during August to October 2005. The survey was repeated at a few sites of the Lake and Southern Zones in June 2006. Three major cassava-growing zones, where cassava is naturally grown, including the Coastal 
Zone (coastline stretch along the Indian Ocean from the northeast in Tanga Region to the southeast in Mtwara), Lake Zone (along the Lake Victoria Basin in the northwest extending to the northern shore of Lake Tanganyika), and Southern Zone (south to west stretching from the Mozambique border through to the shores of Lake Malawi, then to the southern shores of Lake Tanganyika), were covered. Surveyed regions included Coast, Dar es salaam, Morogoro, Lindi, Mtwara, Tanga, and five regions of the Zanzibar archipelago (Coastal Zone); Kagera, Kigoma, Mara, and Mwanza (Lake Zone); and Iringa, Mbeya, Rukwa, and Ruvuma (Southern Zone). Cassava fields were surveyed along accessible roads by stopping at regular intervals of $\approx 100 \mathrm{~km}$. Only fields with $>3$-month-old crops were assessed and sampled. In total, 30 plants were assessed for CBSD foliar and stem incidence and severity based on symptoms, along the diagonal of each field. Based on farmers' names of the cassava being grown, 64 different cultivars were assessed.

Field assessment of CBSD. Field incidence and severity of CBSD were recorded based on shoot, stem, and root symptoms. Incidence was considered as the proportionate percentage of the total number of plants with CBSD symptoms. A Natural Resources Institute (NRI) severity score scale of 1 (no symptoms) through 5 (severe symptoms) for CBSD assessment (11) was used, with minor modifications (Table 1).

Assessments for root symptoms were performed in 81 of the 91 fields as described in Table 1. Permission to dig up plants was sought from the farmers who identified the plants to be dug up and examined. In all, 1 to 15 plants were uprooted in each field and assessed. All the roots on each uprooted stem were counted and cross-section cuts were made at $\approx 2$-cm widths down each tuberous root. The proportion of necrotic roots relative to the total number of roots was used to determine the disease incidence whereas the proportion of tissues damaged by necrosis was used as the root severity score. In plants that were found dually affected by CBSD and CMD, the incidence and severity of CMD was also assessed based on the NRI scale (11). The number of $B$. tabaci adults was counted and recorded from the top five fully expanded leaves of each of the 30 plants visually assessed in each field, then averaged across the field. In fields grown with a mixture of cultivars, the most common cultivar was assessed. The location of each sampling site was recorded using a global positioning system (GPS) (6) and used to generate maps with ArcGIS $9.2(4)$.

Sample collection and handling. Leaf samples collected during the field survey were placed into self-sealable plastic bags and the air was squeezed out. Leaves with CBSD symptoms were preferentially sampled. In the absence of plants with CBSD leaf symptoms, plants with asymptomatic leaves were sampled. The fourth or fifth fully expanded leaf from the top of each plant was removed by the petiole and stored on ice in a cool box for not $>7$ days. Once in the laboratory, samples were ground in liquid nitrogen and stored at $-80^{\circ} \mathrm{C}$.

RNA extraction and reverse-transcription polymerase chain reaction. RNA was extracted from $\approx 0.1 \mathrm{~g}$ of tissue from each of the samples using Pure Link Plant RNA purification reagent, following the manufacturer's instructions (Invitrogen Life Science, Cat. 12322-012). The extracted RNA pellet was dissolved in $35 \mu \mathrm{l}$ of RNase-free water and kept at $-80^{\circ} \mathrm{C}$. Leaf samples from plants known to be positive for CBSVs from Tanzania were included as positive controls. Samples from cassava seedlings grown in a screen-house were used as negative checks.

cDNA synthesis and amplification by reverse-transcriptioin polymerase chain reaction. A one-step reverse-transcription polymerase chain reaction (RT-PCR) reaction was used with Superscript III RT/Platinum Taq Mix System (Invitrogen Life Technologies, Cat. PN.52122) and RNA from the sample in a

TABLE 1. Description of the visual diagnostic scale for Cassava brown streak disease (CBSD) used during the field survey

\begin{tabular}{|c|c|c|c|}
\hline Parameter, plant part ${ }^{\mathrm{a}}$ & Symptomatic or damaged $(\%)$ & Score scale & Description $^{\mathrm{b}}$ \\
\hline \multicolumn{4}{|l|}{ CBSD incidence } \\
\hline \multirow[t]{4}{*}{ Foliar } & 0 & 1 & None of the leaves has chlorosis characteristic for CBSD \\
\hline & $1-5$ & 2 & Very few leaves show faint chlorosis/blotches \\
\hline & $30-50$ & 4 & Half the leaves show chlorosis/blotches \\
\hline & $50-100$ & 5 & Almost all leaves show CBSD chlorosis/blotches \\
\hline \multirow[t]{3}{*}{ Stem } & 0 & 1 & No necrotic spot or lesion characteristic for CBSD on stem \\
\hline & $1-5$ & 2 & A small part of the stem/one branch has necrotic spots \\
\hline & $50-100$ & 5 & Necrotic spots/lesions frequent on all branches/stems \\
\hline \multirow[t]{5}{*}{ Root } & 0 & 1 & None of the roots has necrosis characteristic for CBSD \\
\hline & $0-5$ & 2 & Small number of roots have necrosis characteristic for CBSD \\
\hline & $5-30$ & 3 & Many roots have necrosis characteristic for CBSD \\
\hline & $30-50$ & 4 & Most roots have necrosis characteristic for CBSD \\
\hline & $50-100$ & 5 & Almost/all roots have necrosis characteristic for CBSD \\
\hline \multicolumn{4}{|l|}{ CBSD severity } \\
\hline \multirow[t]{5}{*}{ Stem } & 0 & 1 & No necrotic spot or lesion is seen on stem \\
\hline & $1-5$ & 2 & Slight chlorotic spots on tender portion of the stem \\
\hline & $5-12$ & 3 & Numerous necrotic spots, coalesced to form small lesions \\
\hline & $12-30$ & 4 & Severe necrotic lesions enlarged into streaks \\
\hline & $30-100$ & 5 & Severe necrotic lesions, streaks, withering and die-back \\
\hline \multirow[t]{5}{*}{ Root } & 0 & 1 & None of the roots has necrosis characteristic for CBSD \\
\hline & $1-5$ & 2 & Small portion of roots bears necrotic spots \\
\hline & $5-12$ & 3 & Much root tissue is necrotic \\
\hline & $12-30$ & 4 & Roots mostly necrotic, not suitable for consumption \\
\hline & $30-100$ & 5 & Roots are almost/totally necrotic, started rotting \\
\hline
\end{tabular}

${ }^{a}$ Disease parameter and plant part assessed.

${ }^{\mathrm{b}}$ Characteristic symptoms for CBSD include veinal chlorosis, angular chlorotic blotches, and chlorotic spots (foliar symptoms); necrotic spots, lesions, streaks, withering, and dieback (stem symptoms); and yellow to dark-brown necrotic spots, chlorotic lesions, and corky necrotic masses (roots symptoms). 
GeneAmp PCR system 9700 (Applied Biosystems, UK). All reactions were run in triplicate. The CBSV coat protein $(\mathrm{CP})$ gene-specific primers CBSV 10/F (5'-ATCAGAATAGTGTG ACTGCTGG-3') (691 to 712 nucleotide [nt] binding site) and CBSV 11/R (5'-CCACATTATTATCGTCACCACG-3') (912 to $891 \mathrm{nt}$ binding site) (32) were used. The primers were designed to amplify a 231-bp fragment in the $3^{\prime}$ terminus of the CP gene. PCR conditions were as follows: initial cDNA synthesis and denaturation at $55^{\circ} \mathrm{C}$ for $30 \mathrm{~min}$ and $94^{\circ} \mathrm{C}$ for $1 \mathrm{~min}$, denaturation at $94^{\circ} \mathrm{C}$ for $1 \mathrm{~min}$, annealing at $52^{\circ} \mathrm{C}$ for $1 \mathrm{~min}$, extension at $72^{\circ} \mathrm{C}$ for $1 \mathrm{~min}$ (in 35 cycles), and final extension at $72^{\circ} \mathrm{C}$ for $10 \mathrm{~min}$.

RT-PCR product sequencing and analysis. In total, 43 amplicons were directly sequenced at the Biosciences eastern and central Africa (BecA) platform at the International Livestock Research Institute, Nairobi, Kenya, using an ABI 3130 automatic sequencer. The ABI-generated files were aligned and edited using Sequencher software (version 4.6; Gene Codes Corporation). The sequences were aligned using Clustal X 1.83 (35) and further editing done using Bioedit (9). Each of the sequences was subjected to BLAST searches (44) using the National Center for Biotechnology Information (NCBI) database. Nine selected CP gene sequences for CBSVs collected from Tanzania, Mozambique, and Uganda $(2,31)$ and available in the NCBI database were obtained and aligned together with the 43 sequences (35) using ClustalW (36). Sequences used from the database included AF311052 and AF311053 (Mozambique); AY007597, AY008440, AY008441, and AY008442 (Tanzania); and DQ837302, DQ837303, and DQ837304 (Uganda). Comparable sequences of the two related ipomoviruses, Cucumber vein yellowing virus (accession no. DQ287320) and Sweet potato mild mottle virus (accession no. Z48058), and one potyvirus, Tobacco etch virus (accession no. DQ871334), were also used in the analyses. The phylogenetic analysis was performed through the neighbor-joining method with 1,000 bootstrap replications in PAUP* 4.0 Beta (40). Phylogenetic trees were visualized in Tree View 1.6.6 (8). Multiple comparisons of sequences were performed in MegAlign (DNAStar, Madison, WI) and the percentage similarities among nucleotides estimated.

Data analysis. The survey disease (CBSD and CMD) incidence data were arc sine transformed and the whitefly counts log- transformed by $\log (x+1)$. Analysis was undertaken using GenStat 4.24DE (7) and the Statistical Package for Social Sciences (SPSS 12.0) (37). Pearson's correlation ' $r$ ' analysis was done on all test parameters to determine the significance of relationships between variables.

\section{RESULTS}

Foliar and root incidences and severity of CBSD. The mean field incidences and severities of CBSD on leaves and roots at different altitudes in the surveyed regions are represented (Table 2). The average foliar incidence of CBSD was 0 to $84 \%$ across the surveyed regions. All of the assessed plants in Mbeya Region had zero foliar incidence of CBSD. Highest foliar incidences were observed in all regions of the Coastal Zone and were associated with a mean severity score of 3.1. In all, $5 \%$ of assessed fields in the Coast and Tanga Regions (data not shown) had 100\% foliar incidences. The low-altitude Zanzibar archipelago (below 40 masl) had the highest mean incidence $(85 \%)$ of the disease. In the Lake Zone (despite many sites being located above 1,200 masl), CBSD incidence was $50 \%$ and average foliar severity was 2 . The mean foliar incidence of CBSD (51\%) in the Southern Zone (920 to 1,800 masl) also suggested the presence of the disease across a wide range of altitudes.

Assessment of CBSD root symptoms showed that 4 of the 28 fields in the six regions of the Coastal Zone had $100 \%$ of plants with root necrosis. Tanga Region had the highest mean root incidence (82\%), associated with a mean severity score of 4.3. An average CBSD root incidence of $30 \%$ associated with a mean severity score of 2.3 was recorded in Mbeya, although none of the assessed plants exhibited foliar symptoms. In Mara Region, none of the plants $(36 \%)$ that exhibited CBSD shoot symptoms had root necrosis.

Generally, the Coastal Zone had greater CBSD foliar incidence than the Lake and Southern Zones. The disease parameters (Table 3) indicated that the Coastal Zone had the highest shoot and root incidence and severity of all the zones. Foliar CBSD incidence was lower (27\%) than root incidence $(33 \%)$ in the Southern Zone. Average foliar (38\%) and root $(36 \%)$ incidences were similar for

TABLE 2. Field incidence and severity of Cassava brown streak disease (CBSD) and Cassava mosaic disease (CMD) at different altitudes

\begin{tabular}{|c|c|c|c|c|c|c|c|}
\hline \multirow[b]{2}{*}{ Region } & \multirow[b]{2}{*}{ Fields $^{\mathrm{a}}$} & \multicolumn{6}{|c|}{ Mean (range) $)^{b}$} \\
\hline & & $\begin{array}{l}\text { Altitude } \\
(\text { masl)c }\end{array}$ & $\begin{array}{l}\text { CBSD incidence } \\
(\% \text { foliar })^{\mathrm{d}}\end{array}$ & $\begin{array}{l}\text { CBSD severity } \\
{\text { (foliar })^{\mathrm{e}}}\end{array}$ & $\begin{array}{l}\text { CBSD incidence } \\
(\% \text { roots })^{\mathrm{f}}\end{array}$ & $\begin{array}{l}\text { CBSD severity } \\
\text { (roots) }\end{array}$ & $\begin{array}{l}\text { CMD incidence } \\
(\% \text { foliar })^{\mathrm{h}}\end{array}$ \\
\hline \multicolumn{8}{|l|}{ Coastal Zone } \\
\hline Coast & 5 & 209 & $75(46.7-100)$ & $3.1(2.6-3.6)$ & $10(4-18)$ & $2.3(1-2.7)$ & $39(0-90)$ \\
\hline Morogoro & 1 & 541 & 50 & 2.7 & N/A & N/A & 7 \\
\hline Zanzibar archipelago & 7 & 39 & $85(13.3-100)$ & $3.0(2-3.5)$ & $75(0-100)$ & $3.8(1-4.8)$ & $65(7.1-100)$ \\
\hline Tanga & 5 & 560 & $56(7.1-100)$ & $2.8(2-3.9)$ & $82(0-100)$ & $4.3(0-5.0)$ & $41(6.7-70)$ \\
\hline Lindi & 4 & 95 & $62(27.7-80)$ & $2.9(2.4-3.3)$ & $80(0-100)$ & $3.5(1-4.2)$ & $12(6.7-20)$ \\
\hline Mtwara & 6 & 321 & $43(6.7-93)$ & $2.6(2-3.4)$ & $44(0-100)$ & $3.1(1-4.8)$ & $18(3-50)$ \\
\hline \multicolumn{8}{|l|}{ Lake Zone } \\
\hline Mwanza & 8 & 1,190 & $26(0-63.3)$ & $2.6(1-2.8)$ & $16(9-20)$ & $2.1(2-2.2)$ & $37(13-93.3)$ \\
\hline Kagera & 19 & 1,307 & $26(0-70)$ & $2.3(1-2.76)$ & $42(3.2-53.4)$ & $2.3(2-3.6)$ & $39(6.7-100)$ \\
\hline Kigoma & 5 & 1,313 & $50(0-66.7)$ & $2.2(1-2.5)$ & $25(0-25.2)$ & $2.4(0-2.4)$ & $22(13.3-43.3)$ \\
\hline Mara & 4 & 1,265 & $37(0-56.7)$ & $2.4(2-2.7)$ & 0 & 1 & $28(10-90)$ \\
\hline \multicolumn{8}{|l|}{ Southern Zone } \\
\hline Iringa & 4 & 927 & $21(0-50)$ & $2.4(1-2.9)$ & $23(15-33.3)$ & $2.4(2-2.8)$ & $15(0-26.7)$ \\
\hline Mbeya & 4 & 1,017 & 0 & 1 & $30(0-35.1)$ & $2.3(1-2.6)$ & $52(0-70)$ \\
\hline Rukwa & 2 & 1,322 & $52(50-53)$ & $2.4(2.3-2.4)$ & $25(0-25.2)$ & $2.0(1-2.0)$ & $23(0-23.3)$ \\
\hline Ruvuma & 17 & 947 & $36(0-93.3)$ & $2.5(1-3.2)$ & $39(0-90.2)$ & $2.8(1-3.5)$ & $29(0-83)$ \\
\hline
\end{tabular}

${ }^{a}$ Number of fields assessed.

${ }^{\mathrm{b}}$ Numbers in parentheses refer to the minimum through maximum value recorded. NA = not applicable.

${ }^{c}$ Average elevation (masl = meters above sea level) for all the surveyed fields in each region.

${ }^{d}$ Average of the percentage of total number of plants with CBSD foliar symptoms.

${ }^{\text {e }}$ Severity (mean) of CBSD foliar symptoms on 1-to-5 scale.

${ }^{f}$ Average of the percentage of total number of plants with CBSD symptoms in roots.

${ }^{g}$ Severity (mean) of CBSD symptomatic roots on 1-to-5 scale.

${ }^{\mathrm{h}}$ Average of the percentage of total number of plants with CMD symptoms. 
the country as a whole. The age of the assessed crops was $\approx 8$ months after planting in the Coastal and Lake Zones whereas, in the Southern Zone, the majority of the crop was $\approx 12$ months old. The highest mean CBSD foliar severity (score 2.8) was recorded in the Coastal Zone. Foliar severity scores in the Lake and Southern Zones were 2.5 and 2.6, respectively. Root severity was also highest (3.5) in the Coastal Zone.

Incidences and severity of CMD and whitefly numbers. CMD was recorded in 86 of 91 (94.5\%) surveyed sites (Tables 2 and 3). The mean disease incidence was $30.5 \%$, the highest being in the Lake Zone (35\%). The lowest incidence was observed in Lindi Region (12\%) in the Coastal Zone. CMD severity was similar across the three surveyed zones. Correlation analysis (Table 4) revealed no significant relationship between the disease parameters for CMD and those of CBSD. The numbers of whiteflies were very low across the surveyed sites, except in the Lake Zone, where a mean count of 24 whiteflies per plant was recorded.

Correlation among the disease parameters. Pearson's linear correlation analysis of CBSD indices (Table 4) indicated varied symptom phenotypes in different parts of assessed plants. The results suggested a statistically significant negative correlation between altitude and CBSD foliar, stem, and root incidences and severities, in that an increase in altitude led to decreased incidence and severity of the disease. A statistically significant positive correlation existed between the incidence and severity of CBSD in leaves, stems, and roots. Stem incidence had a positive correlation with incidence and severity of CBSD symptoms on leaves and roots. The incidence of CMD demonstrated a statistically significant positive correlation with the severity of the disease but had no correlation with either CBSD incidences or severities. The recorded number of $B$. tabaci did not suggest any significant relationships with any of the diseases parameters assessed.

Geographical distribution of CBSD. A map was constructed based on the GPS coordinates of sample points and the RT-PCR data (Fig. 1). The data indicated the presence of CBSVs in all cassava-growing regions of Tanzania. Only a few leaf samples were negative for the virus in RT-PCR screening. CBSVs were detected in 22 of $28(78.6 \%)$ samples from the Eastern Zone, 26 of $36(72.2 \%)$ samples from the Lake Zone, and 19 of $27(70.4 \%)$ samples from the Southern Zone. The average detection rate for the country was $73.7 \%$.

Detection of CBSVs and phylogenetic analyses of the amplicons. The RT-PCR test amplified bands of the expected size of $231 \mathrm{bp}$. The phylogenetic analysis of 231-nt CP fragments (Fig. 2) suggested that $\mathrm{CP}$ sequences of CBSVs have some genetic variance, because the partial $\mathrm{CP}$-gene sequences fell within a range of 80.1 to $99.3 \%$ nucleotide similarities. In all, 1 of 43 sequences (FJ687177) clustered in a separate clade. The plant from which this sequence was obtained was located in Masasi, Mtwara (southeastern Tanzania). This sequence was most closely related (93.4\%) to the Ugandan isolates DQ837302, DQ837303, and DQ837304.

All but one of the isolates of CBSVs formed a distinct clade with the six previously published isolates from Mozambique and Tanzania (GenBank accession) in the NCBI database. Isolates in this clade were obtained from different cultivars grown in diverse locations throughout Tanzania (Table 5). One sequence from a sample obtained from Kenya (KECBSV) also grouped with the majority of new Tanzanian isolates.

The nucleotide identities between the new sequences presented in this work and the six reference isolates (AF311052, AF311053,

TABLE 3. Disease, crop age and Bemisia tabaci parameters for the three surveyed zones ${ }^{\mathrm{a}}$

\begin{tabular}{|c|c|c|c|c|}
\hline Diagnostic parameter ${ }^{b}$ & Coastal zone $(n=27)$ & Lake zone $(n=36)$ & Southern zone $(n=28)$ & Country mean \\
\hline Foliar CBSD incidence (\%) & $62(100)$ & $26(70)$ & $27(93.3)$ & 38 \\
\hline Stem CBSD incidence (\%) & $35(86.7)$ & $1(20)$ & $6(56.7)$ & 14 \\
\hline Root CBSD severity & $3.5(5)$ & $2.5(3.6)$ & $2.7(3.5)$ & 2.9 \\
\hline Symptoms on leaf sample (\%) & 100 & 89 & 78 & 89 \\
\hline CBSV positive by RT-PCR (\%) & 79 & 72 & 70 & 74 \\
\hline CMD incidence (foliar) (\%) & 32 & 35 & 24 & 31 \\
\hline CMD severity & 2.9 & 2.9 & 2.6 & 2.8 \\
\hline
\end{tabular}

${ }^{a}$ Maximum value recorded for each parameter is given in parentheses.

${ }^{\mathrm{b}} \mathrm{CBSD}=$ Cassava brown streak disease, $\mathrm{CBSV}=$ Cassava brown streak virus, $\mathrm{RT}-\mathrm{PCR}=$ reverse-transcription polymerase chain reaction, and $\mathrm{CMD}=\mathrm{Cassava}$ mosaic disease.

TABLE 4. Correlation matrix using Cassava brown streak disease (CBSD) and Cassava mosaic disease (CMD) incidence and severity, Bemisia tabaci, crop age, and the field size in sites covered during the survey ${ }^{\mathrm{a}}$

\begin{tabular}{|c|c|c|c|c|c|c|c|c|c|c|c|}
\hline \multirow[b]{2}{*}{ Factor I } & \multicolumn{11}{|c|}{ Factor II } \\
\hline & A & B & $\mathrm{C}$ & $\mathrm{D}$ & $\mathrm{E}$ & $\mathrm{F}$ & $\mathrm{G}$ & $\mathrm{H}$ & $\mathrm{J}$ & K & $\mathrm{L}$ \\
\hline A: Altitude (masl) ${ }^{\mathrm{b}}$ & 1.00 & & $\ldots$ & $\ldots$ & $\ldots$ & $\ldots$ & $\ldots$ & $\ldots$ & $\ldots$ & $\ldots$ & $\ldots$ \\
\hline B: CBSD leaf incidence (\%) & $-0.61 * * *$ & 1.00 & & $\ldots$ & $\ldots$ & $\ldots$ & $\ldots$ & $\ldots$ & $\ldots$ & $\ldots$ & $\ldots$ \\
\hline D: CBSD stem incidence (\%) & $-0.66 * * *$ & $0.76^{* * * *}$ & $0.64 * * *$ & 1.00 & $\ldots$ & $\ldots$ & $\ldots$ & $\ldots$ & $\ldots$ & $\ldots$ & $\ldots$ \\
\hline E: CBSD stem severity & $-0.64 * * *$ & $0.68^{* * * *}$ & $0.67 * * *$ & $0.91 * * *$ & 1.00 & $\ldots$ & $\ldots$ & $\ldots$ & $\ldots$ & $\ldots$ & $\ldots$ \\
\hline F: CBSD root incidence $(\%)$ & $-0.36 * * *$ & $0.39 * * *$ & $0.38^{* * *} *$ & $0.55^{* * *}$ & $0.52 *$ & 1.00 & $\ldots$ & $\ldots$ & $\ldots$ & $\ldots$ & $\ldots$ \\
\hline $\mathrm{K}: \mathrm{CMD}$ severity & $0.201^{\mathrm{NS}}$ & $0.17^{\mathrm{NS}}$ & $0.24 *$ & $0.26 * * *$ & $0.28 * * *$ & $0.07^{\mathrm{NS}}$ & $0.14^{\mathrm{NS}}$ & $0.12^{\mathrm{NS}}$ & $0.56^{* * * *}$ & 1.00 & $\ldots$ \\
\hline L: Crop age (months) & $0.22^{\mathrm{NS}}$ & $-0.18^{\mathrm{NS}}$ & $-0.16^{\mathrm{NS}}$ & $-0.25^{\mathrm{NS}}$ & $-0.25^{*}$ & $-0.11^{\mathrm{NS}}$ & $-0.06^{\mathrm{NS}}$ & $0.24 *$ & $0.10^{\mathrm{NS}}$ & $0.17^{\mathrm{NS}}$ & 1.00 \\
\hline
\end{tabular}

a Partial correlation coefficients $(r)$ among tested variables tested at $P<0.05$ confidence interval; $* * *$ and $*$ indicate significant at $P<0.01$ and 0.05 , respectively; NS = not significant.

${ }^{\mathrm{b}}$ Meters above sea level (masl). 
AY007597, AY008440, AY008441, and AY008442) from Mozambique and Tanzania were all $>80 \%$, except one isolate, FJ687177, which had a lower level of homology (77.9 to $79.4 \%$ ). The nucleotide sequence comparisons between the new isolate sequences in this work and the three reference Ugandan sequences (DQ837302, DQ837303, and DQ837304) revealed lower identities of 77.4 to $93.4 \%$. In our study, the sequences FJ687180, FJ687182, FJ687183, FJ687187, FJ687188, FJ687189, FJ687190, FJ687194, FJ687198, FJ687199, FJ687200, FJ687204, FJ687205, FJ687206, and KECBSV had nucleotide identities $<80 \%$ (77.4 to $79.6 \%$ ) when compared with the Ugandan sequences.

\section{DISCUSSION}

This study reports an extensive study of incidence and severity of CBSD across 19 regions of Tanzania, and explores the relationships between root, stem, and foliar disease incidence and severity. Our results showed that the plant age from which the sample was collected had no effect on detection of CBSVs by RT-PCR. This result corresponded with the field data that indicated that there were no significant correlations between crop age and either incidence or severity of any of the symptom types recorded.
The mean foliar incidence of CBSD (62\%) recorded in the Coastal Zone was high compared with 26 and $27 \%$ found in the Lake and Southern Zones, respectively. It is currently unclear why foliar incidence in the Coastal Zone should be so much greater than that recorded in the other parts of Tanzania, although the relatively recent occurrence of CBSD in the Lake Zone, in particular, suggests that the widespread occurrence of the disease is a recent phenomenon there, in contrast to the Coastal areas, where CBSD has been recognized for $>70$ years (38).

Considering disease indices in each region, the $84 \%$ mean CBSD foliar incidence recorded in Zanzibar (altitude $<200$ masl) was high compared with the $32 \%$ previously reported there (41) and $57 \%$ reported previously at a similar elevation in Mtwara Region (14). This incidence value for Mtwara was the highest recorded for any administrative region of Tanzania during previous assessments of CBSD. Therefore, comparisons with previous surveys in Tanzania $(14,21)$ show clearly that CBSD foliar incidence is increasing throughout the country, suggesting that the disease is continuing to spread.

In the Southern Zone, CBSD symptoms were more apparent in the roots $(33 \%$ incidence) compared with the foliar parts $(27 \%$ incidence). This contrasted with the pattern observed in the other zones, where incidence of foliar symptoms was higher than root-

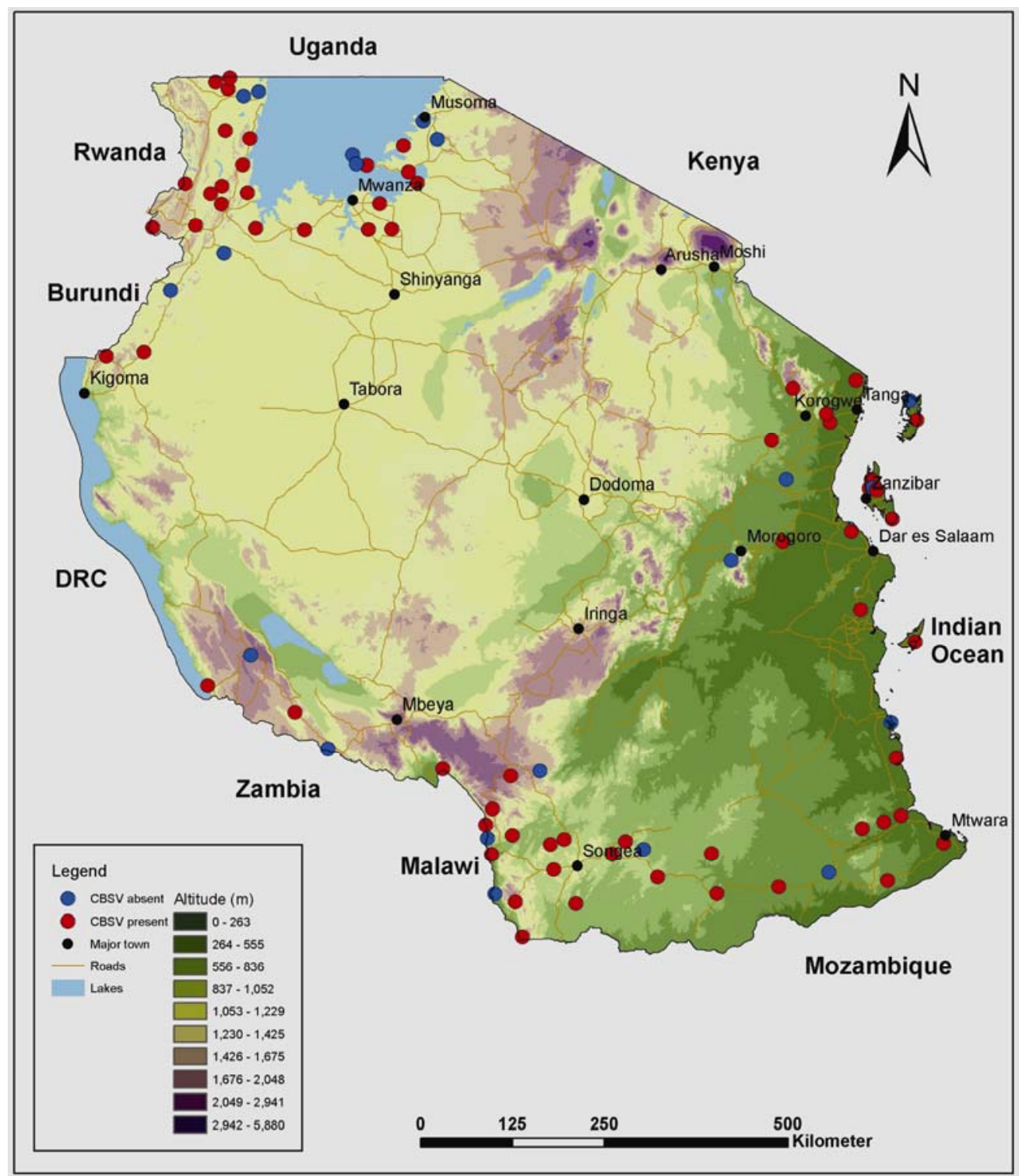

Fig. 1. Distribution of Cassava brown streak virus (CBSV) in Tanzania. Red circles indicate sites from which a CBSV-positive sample was collected and blue circles indicate sites whose samples were CBSV negative based on reverse-transcription polymerase chain reaction detection. 
symptom incidences. This observation is likely to be a consequence of the greater age of plants sampled in the Southern Zone: root symptoms are known to increase in severity as the cassava plant matures (34). Additionally, mature cassava plants tend to shed most symptomatic leaves on the lower part of the plant when the warmer moist season follows the cooler dry season $(10,18,34)$.

Incidences of CBSD symptoms in stems were low compared with foliar and root incidences in all zones. Mean stem incidences of $35 \%$ in the Coastal Zone, $1 \%$ in the Lake Zone, and $6 \%$ in the Southern Zone suggest that stem symptoms alone are not a good diagnostic indicator for CBSD. This concurs with observations by other researchers (34) that stem lesions are not the most characteristic symptom of CBSD.

Despite generally lower incidences of stem symptoms compared with the other symptoms types, correlation analyses confirmed statistically significant positive correlations between all CBSD incidence and severity variables. This is a strong confirmation of earlier studies that have reported associations between CBSD symptom types $(13,34)$. Correlations between shoot and root incidences and severity of CBSD were inconsistent at two sites-Nduna (Ludewa) and Muheza (Tanga)—where plants without foliar or stem symptoms had necrotic roots. This suggests that patterns of symptom expression are cultivar dependent, a characteristic noted earlier by Nichols (34).

This study revealed that CBSD occurs throughout Tanzania, wherever cassava is grown. Earlier studies $(13,14,21,34,41)$ reported the restricted distribution of CBSD to coastal areas, including Zanzibar, with isolated spots in Tabora Region and along the shores of Lake Malawi (21). More recently, occurrences of CBSD and the CBSVs causing it have been reported from midaltitude $(>1,000$ masl) areas of both Uganda and Tanzania $(2,26,27)$. The current findings, however, present the most comprehensive status to date of CBSD and CBSVs in Tanzania and, significantly, highlight their occurrence throughout the cassava-growing areas of the country, including locations up to 1,800 masl.

The presence of CBSD in the Lake Zone has major implications for food security. Based on existing statistics, the Lake Zone ranks second in cassava production in Tanzania after the

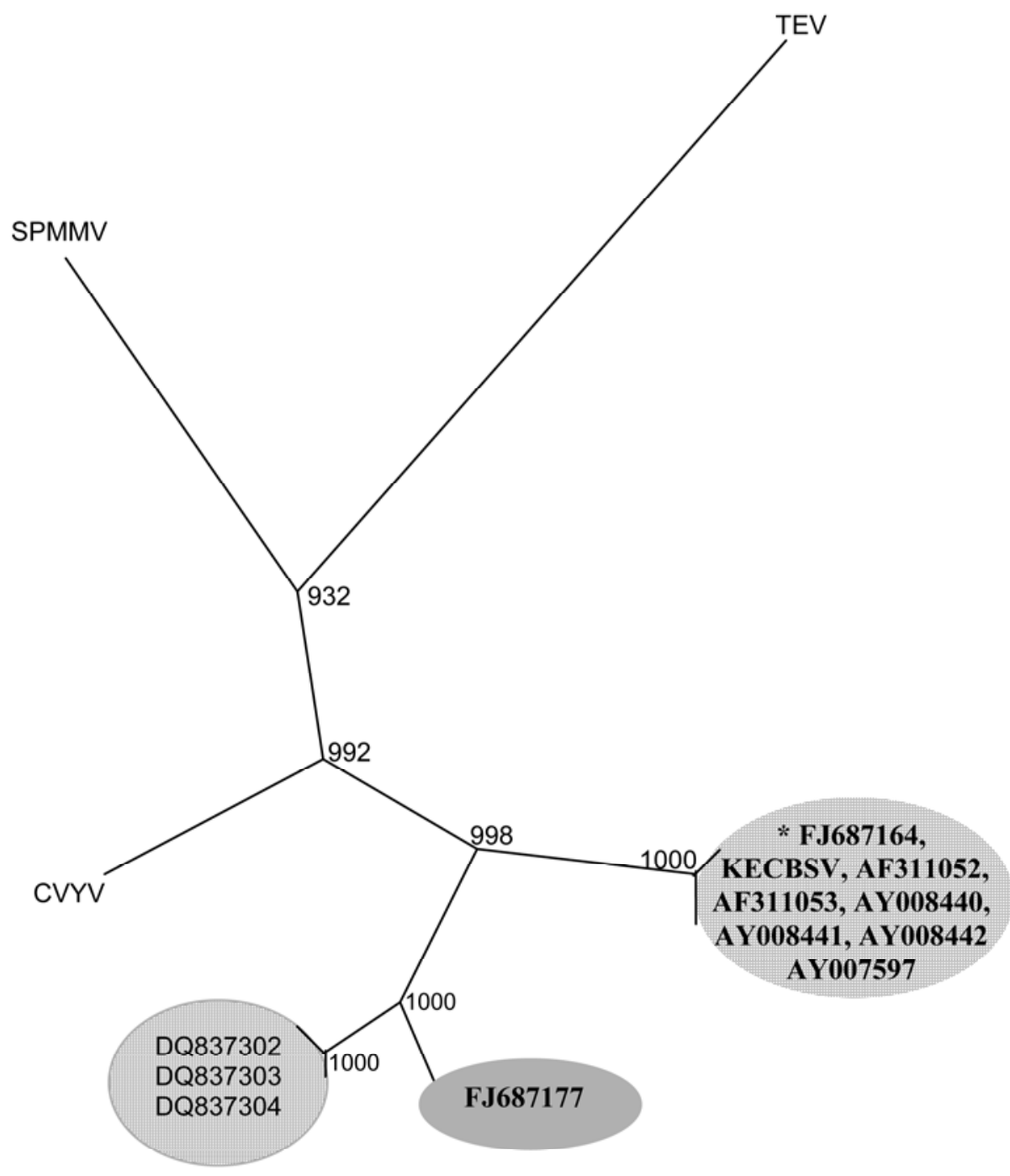

0.1 changes

Fig. 2. Bootstrapped neighbor-joining phylogenetic tree of partial coat protein gene sequences encoding nucleotide sequences of 53 isolates of Cassava brown streak virus. Sequences for the two ipomoviruses (Cucumber vein yellowing virus [DQ287320] and Sweet potato mild mottle virus [Z48058]) and one potyvirus (Tobacco etch virus [DQ871334]) were included as outliers. Only bootstrap values $>900$ are shown. Asterisk (*) represents other sequenced isolates of the same clade which includes the isolates from this study: FJ687165, FJ687166, FJ687167, FJ687168, FJ687169, FJ687170, FJ687171, FJ687172, FJ687173, FJ687174, FJ687175, FJ687176, FJ687178, FJ687180, FJ687181, FJ687182, FJ687183, FJ687184, FJ687185, FJ687186, FJ687187, FJ687188, FJ687189, FJ687190, FJ687191, FJ687192, FJ687193, FJ687194, FJ687195, FJ687197, FJ687198, FJ687199, FJ687200, FJ687201, FJ687202, FJ687203, FJ687204, FJ687205, and FJ687206. FJ687177 clusters separately with the Ugandan clade (DQ837302, DQ837303, and DQ837304). 
Coastal Zone (31). The situation in the Lake Zone is exacerbated by the fact that there are currently no effective sources of resistance, and so-called "tolerant" cultivars that express fewer and milder root symptoms are only available in small quantities (E. Kanju, personal communication). Recent CBSD outbreaks mean that the Lake Zone is likely to be severely impacted by the disease. An added threat to food security in the Lake Zone is the CMD pandemic (22), and most of the local cassava cultivars grown in the zone have limited resistance to CMD (5). The occurrence of the two virus diseases in largely susceptible cassava cultivars will present a real threat to food security in the zone in the near future.
Significant nucleotide sequence variation in the $3^{\prime}$ terminus of the CP was observed among the 43 isolates of CBSVs, demonstrating considerable genetic diversity. Isolate FJ687177 clustered with the three isolates from Uganda (2). The remaining 42 isolates for which sequences were obtained in this study clustered with the reference sequences from Mozambique and Tanzania. Early molecular studies using a small number of isolates from Tanzania and Mozambique led to the initial conclusion that there was a single virus species causing CBSD (32). The apparent divergence of sequences obtained from viruses associated with CBSD in Uganda in 2005 (2), and used as reference sequences in this study, raised the possibility that more than one virus species

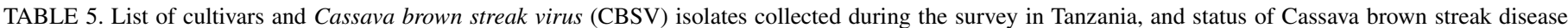
(CBSD) symptoms on the sampled plants ${ }^{\mathrm{a}}$

\begin{tabular}{|c|c|c|c|c|c|}
\hline Sequence name & Source cultivar & District (location) & Foliar symptoms & Root symptoms & Country, source \\
\hline FJ687164 & Albert & SRI-Kibaha & + & + & Tanzania \\
\hline FJ687165 & Albert & Bagamoyo & + & + & Tanzania \\
\hline FJ687166 & Agriculture & Bagamoyo & + & - & Tanzania \\
\hline FJ687167 & Kiba'meno & Muheza & + & + & Tanzania \\
\hline FJ687168 & Msese & Handeni & + & + & Tanzania \\
\hline FJ687169 & M'kuonja & Bagamoyo & + & + & Tanzania \\
\hline FJ687170 & Kipusa & Magharibi & + & + & Tanzania \\
\hline FJ687171 & Mwari & Chakechake & + & + & Tanzania \\
\hline FJ687172 & Boma & Kaskazini B & + & + & Tanzania \\
\hline FJ687173 & Kiroba & Mkuranga & + & + & Tanzania \\
\hline FJ687174 & Mbuyu & Kilwa & + & + & Tanzania \\
\hline FJ687175 & Ayuda & Lindi & + & + & Tanzania \\
\hline FJ687176 & Nanchinyaya & Mtwara & + & + & Tanzania \\
\hline FJ687177 & Mreteta & Masasi & + & + & Tanzania \\
\hline FJ687178 & Mzungu & Mkuranga & + & + & Tanzania \\
\hline FJ687179 & Rwabukindo & Ukerewe & + & + & Tanzania \\
\hline FJ687180 & Toboka & Geita & + & + & Tanzania \\
\hline FJ687181 & Mdalla & Chato & - & - & Tanzania \\
\hline FJ687206 & Bukalasa & Bukoba & + & + & Tanzania \\
\hline FJ687182 & Bukalasa & Bukoba & + & + & Tanzania \\
\hline FJ687183 & Unknown & Misenyi & + & - & Tanzania \\
\hline FJ687184 & Unknown & Misenyi & + & + & Tanzania \\
\hline FJ687185 & Unknown & Muleba & + & + & Tanzania \\
\hline FJ687186 & Kataakya & Muleba & + & + & Tanzania \\
\hline FJ687187 & Lumala & Muleba & + & - & Tanzania \\
\hline FJ687188 & TMS 4(2) 1425 & Biharamulo & + & + & Tanzania \\
\hline FJ687189 & TMS 4(2) 1425 & Ngara & + & + & Tanzania \\
\hline FJ687190 & Ndelela & Kasulu & + & - & Tanzania \\
\hline FJ687191 & Kongo & Kigoma & + & - & Tanzania \\
\hline FJ687192 & Muganda & Misungwi & + & + & Tanzania \\
\hline FJ687193 & Lyongo & Magu & + & - & Tanzania \\
\hline FJ687194 & Lwabakanga & Bunda & - & - & Tanzania \\
\hline FJ687195 & Kachaga & Musoma & + & - & Tanzania \\
\hline FJ687196 & Mipeta & Mbinga & + & - & Tanzania \\
\hline FJ687197 & Mtutuma & Ludewa & + & + & Tanzania \\
\hline FJ687198 & Paliani & Mbinga & + & - & Tanzania \\
\hline FJ687199 & Mwaya & Namtumbo & + & + & Tanzania \\
\hline FJ687200 & Kigoma & Tandahimba & + & - & Tanzania \\
\hline FJ687201 & Mwaya & Ruvuma & + & - & Tanzania \\
\hline FJ687202 & Dide red & Tunduru & + & - & Tanzania \\
\hline FJ687203 & Kayumu & Songea & + & + & Tanzania \\
\hline FJ687204 & Kifuu & Ludewa & + & + & Tanzania \\
\hline FJ687205 & Kabumba & Sum'wanga & + & - & Tanzania \\
\hline \multicolumn{6}{|l|}{ Reference isolates } \\
\hline$\pm \mathrm{KECBSV}$ & Guzo & N/A & + & N/A & Kenya \\
\hline *AF311052 & Mulaleia & Zambezia & + & N/A & Mozambique \\
\hline *AF311053 & Fernando & Zambezia & + & N/A & Mozambique \\
\hline *AY007597 & Unknown & Unknown & N/A & N/A & Unknown \\
\hline *AY008440 & Mukukumkuku & Unknown & + & N/A & Tanzania \\
\hline *AY008441 & Vumbi & Unknown & + & N/A & Tanzania \\
\hline *AY008442 & Kibaha & SRI-Kibaha & + & N/A & Tanzania \\
\hline *DQ837302 & TMS I 92/0057 & Mukono & + & N/A & Uganda \\
\hline *DQ837303 & Ebwan'tereka & Namulonge & + & N/A & Uganda \\
\hline *DQ837304 & TME 204 & Wakiso & + & N/A & Uganda \\
\hline
\end{tabular}

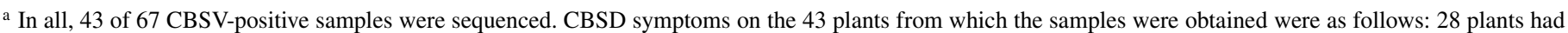
both foliar and root symptoms, 13 had only foliar symptoms, 2 plants were symptomless, and none of the plants had root symptoms without foliar symptoms. Symbols: + indicates presence, - indicates absence, N/A indicates not applicable, \pm indicates CBSV coat protein (CP) gene sequences for an isolate from Kenya, and * indicates already published CBSV CP gene sequences obtained from National Center for Biotechnology Information public database. 
was associated with the disease. ICTV rules on speciation within the genus Ipomovirus, based on full CP gene sequences (17), indicate that strains within the same species should maintain $>80 \%$ nucleotide identity. However, if the $\mathrm{CP}$ gene sequence identity is $<80 \%$, a new Ipomovirus $\mathrm{sp}$. may be described. Analyses of nucleotide sequences of seven full-length genomes of CBSVs obtained from Kenya, Tanzania, Mozambique, Uganda, and Malawi $(30,42)$ clearly demonstrated two distinct species of CBSVs. Clade 1 (UCBSV) comprised isolates from Kenya, Uganda, Malawi, and northwestern Tanzania sharing 87 to $95 \%$ nucleotide sequence identities, while clade 2 (CBSV isolates) included isolates from coastal regions of Mozambique and Tanzania (70\% nucleotide sequence identity with clade 1 isolates). Although there was a proposal that clade 2 viruses be named Cassava brown streak Mozambique virus (43), ICTV has now designated clade 1 viruses as UCBSV and clade 2 viruses as CBSV (27). A recent study on the evolution of CBSD has implied an ongoing but different evolution of CBSV and UCBSV, with evidence for homologous recombination between isolates within the same species but no evidence for heterologous recombination between species (28). The sizes of the genomes from clade 1 (9,070 nt) and clade 2 (8,997 to 9,008 nt), and the CP molecules (43 and $45 \mathrm{kDA}$ for clades 1 and 2, respectively), also differed between viruses from the two clades (43). Differences in amino acid sequences of the full CP (79 to $81 \%$ amino acid identity between clades 1 and 2) provided further evidence for the existence of two species (26). From the current study, isolate FJ687177, from Masasi in Southern Tanzania, clusters with the three reference isolates (DQ837302, DQ837303, and DQ837304) from Uganda. FJ687177 falls within the UCBSV clade, although the fact that it forms a distinct branch suggests that it may be a distinct UCBSV strain. A more definitive identification will require full $\mathrm{CP}$ or genome sequence data.

The similarity of CBSV isolates across Tanzania may be due to the extensive exchange of cassava planting materials within and between the farming communities (29). Because cassava is a vegetatively propagated crop, virus spread might have occurred inadvertently through the exchange of infected cuttings. Further sequencing of isolate FJ687177 to establish its identity is required, and additional survey work is needed to establish whether it occurs more widely in the southern part of Tanzania or elsewhere in East Africa. Geographically limited studies using material sampled in 2007 to 2010 have noted the occurrence of both UCBSV and CBSV from the Lake Zone and central and southern parts of the Coastal Zone. The absence of UCBSV from the Lake Zone in the current study (with sampling in 2005 to 2006) raises the intriguing possibility that increases in CBSD incidence in recent years may be primarily associated with spread of UCBSV. Surveys repeated at regular intervals will be required to confirm whether or not this is the case. A relatively rapid change in the relative distributions of the two species of CBSVs in Tanzania suggests that the whitefly vector, B. tabaci, may be playing a significant role in the regional epidemiology of CBSD. It is notable that large increases in whitefly populations have been reported throughout the Great Lakes region of East and Central Africa from the 1990s to the present (20). These "superabundant" whitefly populations have previously been implicated as a driving factor in the regional spread of the CMD pandemic (20).

Although CBSVs have been detected from Manihot glaziovii (Müll. Arg.), there have currently been no detections from wild indigenous weed species. This may be due, in part, to the fact that there have not been any specific studies that have tried to search for wild weed hosts. In the absence of this information, and with the current limited knowledge of the variability within populations of CBSVs, it is not possible to speculate about the possible origin of the CBSVs reported in this study or elsewhere. More comprehensive sequence information from all the regions in which CBSVs occur will be required before any conclusions can be made about the evolutionary history of the viruses causing CBSD.

The current study represents the earliest identification and confirmation of the occurrence of CBSVs in the Lake Zone and southwestern parts of Tanzania. The majority of local cultivars appear to be susceptible to CBSD. The incidence and severity levels of the disease indicate a new epidemic in the Lake Zone of Tanzania, which may exacerbate the food shortages already caused by the CMD pandemic. In view of the findings in this study, further similar work in neighboring countries (particularly Burundi, Democratic Republic of Congo, and Rwanda) is warranted in order to gauge the full extent of the spread of CBSVs and their genetic diversity in the East African region. Furthermore, more detailed characterization of these viruses will provide the key benefits of facilitating the development of improved diagnostics as well as guiding the development of novel control strategies such as transgenic virus resistance. Effective management of CBSD will be critical for the long-term future of cassava production in East and Central Africa and will depend on the deployment of appropriate combinations of all available control strategies.

\section{ACKNOWLEDGMENTS}

G. Momanyiauthor passed away before completion of this study but his contribution to its success is highly appreciated. We thank the International Institute of Tropical Agriculture (IITA) for funding this study; Mikocheni Agricultural Research Institute, Dar es Salaam, Tanzania, for providing the laboratory facilities; the Tanzania national root crop scientists, research authorities, and agricultural extension staff for their support with field work; E. Kanju of IITA Tanzania for technical guidance; H. Bouwmeester for technical assistance in producing the map; D. J. Kim, IITA-Kenya, Nairobi, for sequencing of CBSVs; and E. Kimani of the Kenya Plant Health Inspectorate Services and T. Munga of the Kenya Agricultural Research Institute, Mtwapa, for assistance in providing the Kenyan isolate (KECBSV).

\section{LITERATURE CITED}

1. Adams, M. J., Antoniw, J. F., and Fauquet, C. M. 2005. Molecular criteria for genus and species discrimination within the family Potyviridae. Arch. Virol. 150:459-479.

2. Alicai, T., Omongo, C. A., Maruthi, M. N., Hillocks, R. J., Baguma, Y., Kawuki, R., Bua A., Otim-Nape, G. W., and Colvin, J. 2007. Re-emergence of cassava brown streak disease in Uganda. Plant Dis. 91:24-29.

3. EARRNET. 2005. Statement on the Consequences of New Spread of Cassava Brown Streak Virus Disease for Movement of Cassava Germplasm in the East and Central African Region. International Institute of Tropical Agriculture. www.iita.org.

4. Environmental System Research Institute (ESRI), 2006. ArcMap 9.2 GIS. www.esri.com/software/arcgis/.

5. Fargette, D., Colon, L. T., Bouveau, R., and Fauquet, C. 1996. Components of resistance to African cassava mosaic virus. Eur. J. Plant Pathol. 102:645-654.

6. Garmin Ltd. 2006. eTrex GPS 12, Personal Navigator. www.garmin.com/ products/etrex.

7. GenStat, 4.24DE. 2005. The GenStat Discovery, 2nd ed. Lawes Agricultural Trust. Rothamstead Experimental Station. http://discovery.genstat.co.uk.

8. Hall, B. G. 2004. Phylogenetic Trees Made Easy, 2nd ed. Sinauer Associates, Inc., Sunderland, MA.

9. Hall, T. A. 1999. BioEdit: A user-friendly biological sequence alignment editor and analysis program for Windows 95/98/NT. Nucleic Acids Symp. Ser. 41:95-98.

10. Hillocks, R. J. 1997. Cassava virus disease and their control with special reference to southern Tanzania. Int. Pest Manage. Rev. 2:125-138.

11. Hillocks, R. J., and Jennings, D. L. 2003. Cassava Brown Streak Disease: A review of present knowledge and research needs. Int. J. Pest Manage. 49:225-234.

12. Hillocks, R. J., Raya, M. D., Mtunda, K., and Kiozia, H. 2001. Effects of cassava brown streak virus disease on yield and quality of cassava in Tanzania. J. Phytopathol. 149:389-394.

13. Hillocks, R. J., Raya, M. D., and Thresh, J. M. 1996. The association between root necrosis and above-ground symptoms of brown streak virus infection of cassava in southern Tanzania. Int. J. Pest Manage. 42:285-289. 
14. Hillocks, R. J., Raya, M. D. and Thresh, J. M. 1999. Distribution and symptoms expression of cassava brown streak disease in southern Tanzania. Africa. J. Root Tuber Crops 3:57-61.

15. Hillocks, R. J., and Thresh, J. M. 1998. Cassava Mosaic and Cassava Brown Streak Virus Diseases in Africa: A Comparative Guide to Symptoms and Aetiologies. Natural Resources Institute, UK.

16. Hillocks, R. J., Thresh, J. M., Tomas, J., Botao, M., Macia, R., and Zavier, R. 2002. Cassava brown streak disease in northern Mozambique. Int. J. Pest Manage. 48:179-182.

17. ICTV. 2005. Virus Taxonomy; Classification and Nomenclature of Viruses, 8th Report of the ICTV. C. M. Fauquet, M. A. Mayo, J. Maniloff, U. Desselberger, and L. A. Balls, eds. Elsevier Academic Press, San Diego, CA.

18. Jennings, D. L. 1957. Further studies in breeding cassava for virus resistance. East Afr. Agric. J. 22:213-219.

19. Legg, J. P., and Hillocks, R. J., eds. 2003. Cassava brown streak virus disease: Past, present and future. In: Proc. Int. Workshop, Mombasa, Kenya, Natural Resources International Limited, Aylesford, UK.

20. Legg, J. P., Owor, B., Sseruwagi, P., and Ndunguru, J. 2006. Cassava mosaic virus disease in East and Central Africa: epidemiology and management of a regional pandemic. Adv. Virus Res. 67:355-418.

21. Legg, J. P., and Raya, M. D. 1998. Survey of cassava virus diseases in Tanzania. Int. J. Pest Manage. 44:17-23.

22. Lennon, A. M., Aiton, M. M., and Harrison, B. D. 1985. Cassava viruses from Africa. In: Annual Report of the Scottish Crop Research Institute. SCRI, Dundee, UK.

23. Maruthi, M. N., Hillocks, R. J., Mtunda, K., Raya, M. D., Muhanna, M., Kiozia, H., Rekha, A. R, Colvin, J., and Thresh, J. M. 2005. Transmission of Cassava brown streak virus by Bemisia tabaci (Gennadius). J. Phytopathol. 153:307-312.

24. Matthews, R. E. F. 1991. Plant Virology, Third ed. Academic Press Inc., UK.

25. Mbanzibwa, R. D., Tian, Y., Mukasa, S. B., and Valkonen, J. P. T. 2009. Cassava brown streak virus (Potyviridae) encodes a putative Maf/HAM1 pyrophosphatase implicated in reduction of mutations and a P1 proteinase that suppresses RNA silencing but contain no HC-Pro. J. Virol. 83:69346940.

26. Mbanzibwa, D. R., Tian, Y. P., Tugume, A. K., Mukasa S. B., Tairo, F., Kimanywa, S., Kulaya, A., and Valkonen, P. T. J. 2009. Genetically distinct strains of Cassava brown streak virus in the Lake Victoria Basin and the Indian Ocean Coastal areas of East Africa. Arch. Virol. 154: 353-359.

27. Mbanzibwa, D. R., Tian, Y. P., Tugume, A. K., Mukasa, S. B., Tairo, F., Kyamanywa, S., Kullaya, A., and Valkonen, J. P. T., 2010. Simultaneous virus-specific detection of the two cassava brown streak-associated viruses by RT-PCR reveals wide distribution in East Africa, mixed infections and infections in Manihot glaziovii. J. Virol. Methods 171:394-400.

28. Mbanzibwa, D. R., Tian, Y. P., Tugume, A. K., Patil, B. L., Yadav, J. S., Bagewadi, B., Abarshi, M. M., Aliai, T., Changadeya, W., Mkumbira, J.,
Muli, M. B., Mukasa, S. B., Tairo, F., Baguma, Y., Kyamanywa, S., Kullaya, A., Maruthi, M. N., Fauquet, C. M., and Valkonen, J. P. T., 2011. Evolution of cassava brown streak-associated viruses. J. Gen. Virol. 92:974-987.

29. Mkamilo, G. S. 2005. Current status of cassava improvement programme in Tanzania. Presented at: Workshop on Molecular Marker Assisted and Participatory Plant Breeding, Dar es Salaam, Tanzania.

30. Monger, W. A., Alicai, T., Ndunguru, J., Kinyua Z. M., Pots, M., Reeder, R. H., Miano, D. W., Adams, I. P., Boonham, N., Glover, R. H., and Smith, J. 2010. The complete genome sequence of the Tanzanian strain of Cassava brown streak virus and comparison with the Ugandan strain sequence. Arch. Virol. 155:429-433.

31. Monger, W. A., Seal, S., Cotton, S., and Foster, G. D. 2001. Identification of different isolates of Cassava brown streak virus and development of diagnostic test. Plant Pathol. 50:768-775.

32. Monger, W. A., Seal, S., Isaac, A. M., and Foster, G. D. 2001. Molecular characterization of Cassava brown streak virus coat protein. Plant Pathol. 50:527-534.

33. Mtunda, K. J., Muhana, M., Raya, M. D., and Kanju, E. E. 2003. Current status of Cassava brown streak virus disease in Tanzania. Pages 7-11 in: Cassava brown streak virus Disease: Past, Present and Future. J. P. Legg and R. J. Hillocks, eds. Proc. Int. Workshop, Mombasa, Kenya. Natural Resources International Limited, Aylesford, UK.

34. Nichols, R. F. J. 1950. The brown streak disease of cassava: Distribution, climatic effect and diagnostic symptoms. East Afr. Agric. J. 15:154-160.

35. Rwegasira, G. M., Rey, M. E. C., Legg, J. P., and Herron, C. M. 2009. Cassava brown streak virus sequences for 43 isolates from Tanzania. http://www.ncbi.nlm.nih.gov/.

36. Sci-biology. 2005. Graphical Interface for the ClustalW multiple alignment program. http://www.clustal.org.

37. SPSS. 2003. SPSS, 12.0. SPSS Inc., Chicago. http://www.spss.com.

38. Storey, H. H., 1936. Virus diseases of East African plants VI. A progress report on studies of the disease of cassava. East. Afr. Agric. J. 12:34-39.

39. Storey, H. H. 1939. Report on the plant pathologist. East Afr. Agric. Res. Stn. 1939.

40. Swafford, D. 2003. Phylogenetic Analysis Using Parsimony (PAUP* 4.0 Beta). Sinauer Associates, Inc., Sunderland, MA. http://paup.csit.fsu.edu/ about.html.

41. Thresh, J. M., and Mbwana, M. W. 1998. Cassava mosaic and cassava brown streak in Zanzibar. Roots 5:6-8.

42. Winter, S., Koerbler, M., Stein, B., Pietruszka, A., and Butgereitt, A. 2008. The cassava brown streak viruses infecting cassava in East Africa. In: First Sci. Meet. Global Cassava Partnership GCP-I, Ghent, Belgium.

43. Winter, S., Koerbler, M., Stein, B., Pietruszka, A., Paape, M., and Butgereitt, A. 2010. The analysis of Cassava brown streak viruses reveals the presence of a distinct virus species causing cassava brown streak in East Africa. J. Gen. Virol. 91:1365-1372.

44. Zhang, Z., Schwartz, S., Wagner, L., and Miller, W. 2000. A greedy algorithm for aligning DNA sequences. J. Comput. Biol. 7:203-214. 